\title{
Relationship between air pollution, lung function and asthma in adolescents
}

\section{Talat Islam, W James Gauderman, Kiros Berhane, Rob McConnell, Ed Avol, John M Peters, Frank D Gilliland}

See end of article for authors' affiliations

Correspondence to: Dr Frank Gilliland, Department of Preventive Medicine, Keck School of Medicine, 1540 Alcazar Street, CHP 236, Los Angeles California 90033, USA; gillilan@usc.edu

Received 28 February 2007 Accepted 18 April 2007 Published Online First 21 May 2007

\begin{abstract}
Background: The interrelationships between air pollution, lung function and the incidence of childhood asthma have yet to be established. A study was undertaken to determine whether lung function is associated with new onset asthma and whether this relationship varies by exposure to ambient air pollutants.

Methods: A cohort of children aged 9-10 years without asthma or wheeze at study entry were identified from the Children's Health Study and followed for 8 years. The participants resided in 12 communities with a wide range of ambient air pollutants that were measured continuously. Spirometric testing was performed and a medical diagnosis of asthma was ascertained annually. Proportional hazard regression models were fitted to investigate the relationship between lung function at study entry and the subsequent development of asthma and to determine whether air pollutants modify these associations.

Results: The level of airway flow was associated with new onset asthma. Over the 10th-90th percentile range of forced expiratory flow over the mid-range of expiration $\left(\mathrm{FEF}_{25-75}, 57.1 \%\right)$, the hazard ratio (HR) of new onset asthma was 0.50 (95\% $\mathrm{Cl} 0.35$ to 0.71$)$. This protective effect of better lung function was reduced in children exposed to higher levels of particulate matter with an aerodynamic diameter $<2.5 \mu \mathrm{m}\left(\mathrm{PM}_{2.5}\right)$. Over the 10th-90th percentile range of $\mathrm{FEF}_{25-75}$, the $\mathrm{HR}$ of new onset asthma was $0.34(95 \% \mathrm{Cl} 0.21$ to 0.56$)$ in communities with low $\mathrm{PM}_{2.5}\left(<13.7 \mu \mathrm{g} / \mathrm{m}^{3}\right)$ and $0.76(95 \% \mathrm{Cl} 0.45$ to 1.26$)$ in communities with high $\mathrm{PM}_{2.5}$ $\left(\geqslant 13.7 \mu \mathrm{g} / \mathrm{m}^{3}\right)$. A similar pattern was observed for forced expiratory volume in $1 \mathrm{~s}$. Little variation in HR was observed for ozone.

Conclusion: Exposure to high levels of $\mathrm{PM}_{2.5}$ attenuates the protective effect of better lung function against new onset asthma.
\end{abstract}

A sthma is a major cause of childhood morbidity and has high social and economic costs. ${ }^{1}$ Current research suggests a complex aetiological pathway for asthma, ${ }^{2}$ and there is emerging evidence that air pollution is one environmental factor that may be involved in the pathogenesis of the disease. ${ }^{3}$ Both indoor pollution ${ }^{4}$ and traffic exposure ${ }^{5}$ have been associated with an increased risk of asthma in children. In the Children's Health Study (CHS), ${ }^{67}$ a longitudinal cohort study of air pollution, genetics and respiratory health, we have reported that the genetic risk factors for asthma depend upon exposure to ambient air pollution. ${ }^{8}$ For example, we found that the protective effect of a polymorphism in the promoter region of tumour necrosis factor $\alpha$ was attenuated by ambient ozone levels. This suggests that air pollution may overwhelm the protective effects of certain alleles and increase the risk of asthma in a subset of children.

Based on these observations, we suggest that air pollution modifies the risk of asthma associated with other constitutive factors such as lung function which may reflect an integrative index of respiratory health. The evidence supports a protective role for high lung function in asthma development. Flow rates during the first year of life have been associated with the subsequent onset of asthma and persistent wheeze in some ${ }^{9}$ but not all studies. ${ }^{11}$ However, if different environmental exposures such as air pollution attenuate the protective effect of better lung function in some studies, these differences might be expected to occur based on pathophysiology. One class of pollutants of interest is ambient particulate matter which has been associated with small airway remodelling (a hallmark of asthma), ${ }^{12}$ low airway flow rates ${ }^{13}{ }^{14}$ and impaired lung function growth. ${ }^{15}$ These studies suggest that there may be joint effects of air pollution and lung function on asthma.
To assess the hypothesis that higher lung function is associated with reduced risk for childhood asthma, but that ambient air pollution attenuates this effect, we examined air pollution, lung function and health data from the CHS. Among children without asthma at study entry, we examined the relationship between spirometric measurements of lung volumes and airway flows and the subsequent risk of new onset asthma in communities with different levels of air pollution.

\section{METHODS}

\section{Study design and cohort}

The design, methods and characteristics of the CHS have been described previously. ${ }^{67}$ Briefly, school children were enrolled into the study in 1993 from 12 communities in southern California (selected on the basis of different ambient pollution levels). At study entry parents or guardians of the children completed a questionnaire regarding children's medical history and sociodemographic factors (for details see Methods in online supplement available at http://thorax.bmj.com/supplemental). This study was approved by the Institutional Review Board of University of Southern California.

To provide a targeted age range (9-10 years of age at baseline) in which to assess the effect of lung function on the risk of asthma from childhood through adolescence, the analysis was restricted to fourth grade cohorts who (1) were free of any wheezing or physician-diagnosed asthma at study

Abbreviations: $\mathrm{FEF}_{25-75}$, forced expiratory flow over the mid-range of expiration; $F V_{1}$, forced expiratory volume in $1 \mathrm{~s}$; FVC, forced vital capacity; $\mathrm{NO}_{2}$, nitrogen dioxide; $\mathrm{O}_{3}$, ozone; $\mathrm{PM}_{10}, \mathrm{PM}_{2.5}$, particulate matter with an aerodynamic diameter $<10 \mu \mathrm{m}$ and $<2.5 \mu \mathrm{m}$ 
entry, (2) could perform adequate lung function manoeuvres at study entry and (3) had at least one follow-up assessment $(\mathrm{n}=2057)$.

\section{New onset asthma}

Children who were disease-free at baseline and reported physician-diagnosed asthma at annual follow-up testing were classified as having new onset asthma. As the follow-up occurred annually, the date of onset was assigned to the midpoint of the interval between the interview date when asthma diagnosis was first reported and the previous interview date. During the interview the children also provided information regarding recent use of any inhaled asthma medication.

\section{Air pollution data}

Ambient levels of ozone $\left(\mathrm{O}_{3}\right)$, nitrogen dioxide $\left(\mathrm{NO}_{2}\right)$, particulate matter with an aerodynamic diameter $<10 \mu \mathrm{m}$ $\left(\mathrm{PM}_{10}\right)$ and $<2.5 \mu \mathrm{m}\left(\mathrm{PM}_{2.5}\right)$, acid vapour and elemental and organic carbon in each of the 12 communities were measured at air monitoring sites from 1994 onwards. Long-term mean pollutant levels (from 1994 to the end of 2003) were calculated for use in the statistical analysis. Owing to a high correlation between $\mathrm{PM}_{2.5}, \mathrm{NO}_{2}$, acid vapour, $\mathrm{PM}_{10}$ and elemental and organic carbon (but not ozone), these can be considered as a correlated non-ozone "package" of pollutants with a similar pattern relative to each other across the 12 communities. Communities defined as "high" or "low" based on any of the non-ozone "package" of pollutants were the same for all of the correlated pollutants (for details see Methods section in online supplement available at http://thorax.bmj.com/supplemental).

\section{Lung function measurement}

Data on children's lung function were collected by trained field technicians who visited the schools annually. Maximal effort spirometric tests, standing height and weight were measured. Details regarding the lung function testing protocol have been published previously. ${ }^{6}$ These activities covered the period 19932004. Three measures of lung function were analysed: forced vital capacity $(\mathrm{FVC})$, forced expiratory volume in $\mathrm{l} \mathrm{s}\left(\mathrm{FEV}_{1}\right)$ and forced expiratory flow over the mid-range of expiration $\left(\mathrm{FEF}_{25-75}\right)$. Sex-specific percentage predicted lung function values were calculated using linear regression (for detail see Methods section in online supplement available at http:// thorax.bmj.com/supplemental).

The percentage predicted lung function values were scaled to the 10th-90th percentile range of the corresponding lung function, and also categorised into three groups based on cutoff points that provided an adequate distribution for analyses. The categories were $<90 \%, 90-100 \%$ and $>100 \%$ of predicted for $\mathrm{FVC}$ and $\mathrm{FEV}_{1}$ and <100\%, $100-120 \%$ and $>120 \%$ for $\mathrm{FEF}_{25-75}$.

\section{Sociodemographic and medical history information}

Personal information such as ethnicity, birth weight, premature birth, maternal smoking during pregnancy and allergy histories was collected at study entry. A family history of asthma was defined as asthma in any of the biological parents. Body mass index (BMI) was categorised into age- and sex-specific percentiles based on the Centers for Disease Control (CDC) BMI growth charts using 1-month age intervals. ${ }^{16}$ Participants with BMI at or above the 85th percentile were classified as overweight. These personal characteristics and household and indoor exposures (pets, pests, humidifier use and household smoking) were considered as potential effect modifiers as well as confounders in the analysis.

\section{Statistical methods}

We fitted Cox proportional hazards models with sex- and agespecific (age defined as integer age at study entry) baseline hazards to investigate the association between new onset asthma and lung function at study entry. Initially, we fitted lung function as both categorical and continuous terms. In the absence of any non-linear association between lung function and new onset asthma (tested by adding quadratic terms for the lung functions in the continuous models as well as by fitting models with categorical lung function terms) based on likelihood ratio tests, we report results using lung function as a continuous term. The hazard ratio (HR) can be interpreted as the change in risk of new onset asthma as the lung function increases over the 10th-90th percentile range of the corresponding lung function. We also fitted proportional hazard models treating annual lung function as 1- or 2-year lagged time-dependent covariates. All models were adjusted for community and race/ethnicity. Additional covariates were considered for inclusion in the model based on whether their inclusion changed the lung function effect estimate by more than $10 \%$. Heterogeneity of associations among subgroups was assessed by comparing appropriate models with and without interaction terms.

To assess the effect of ambient air pollution on the relationship between lung function and new onset asthma, we estimated the heterogeneity of association using community levels of air pollutants measured at one monitor in each community. To address this issue we fitted hierarchical twostage models to these time-dependent data (for details see Methods section in online supplement available at http:// thorax.bmj.com/supplemental). ${ }^{17}$

All analyses were conducted using SAS software (SAS Institute, Cary, NC, USA) Version 9.1. All hypothesis testing was conducted assuming a 0.05 significance level and a twosided alternative hypothesis.

\section{RESULTS}

\section{Subject characteristics}

Most of the 2057 disease-free children included in this analysis were 10 years of age or less at study entry and non-Hispanic white (table 1). Most children had health insurance and parents with at least a high school education. The median and mean years of follow-up were 8 and 6.5 years, respectively, for the 1993 cohort and 8 and 6.2 years, respectively, for the 1996 cohort ( 8 years maximum possible for both cohorts). The completeness of the follow-up data was calculated as the ratio of observed and maximum possible years of follow-up. Overall, the children were followed for $79 \%$ of the possible time of observation over the 8-year period of the study. The completeness of follow-up did not vary substantially across any of the subgroups (table 1). Based on telephone interviews with the families of subjects with asthma or wheeze at study entry who left the schools, the loss to follow-up was mainly due to employment-related moves of families out of the school catchment area (data not shown). Thus, the loss to follow-up was random and not related to any exposure or disease status.

There was no difference between the children included in the study and those who were excluded owing to insufficient lung function assessments $(n=521)$ with respect to age, sex, in utero and environmental exposure to smoking, parental education, parental asthma status and health insurance. However, those included in the study were slightly more likely to be non-Hispanic white, to have dogs at home and a higher parental income than those with insufficient lung function assessments (see table E3 in online supplement available at http://thorax.bmj.com/supplemental). 
Table 1 Selected characteristics of participants with no history of physician-diagnosed asthma at study entry

\begin{tabular}{|c|c|c|}
\hline $\begin{array}{l}\text { Selected characteristics at } \\
\text { study entry* }\end{array}$ & N (2057) & $\begin{array}{l}\text { Ratio of observed } \\
\text { to total possible } \\
\text { person-yearst }\end{array}$ \\
\hline \multicolumn{3}{|l|}{ Age at entry (years) } \\
\hline $7-9$ & 1441 & 0.80 \\
\hline 10 & 557 & 0.79 \\
\hline $11-12$ & 59 & 0.67 \\
\hline \multicolumn{3}{|l|}{ Race/ethnicity } \\
\hline Non-Hispanic white & 1094 & 0.80 \\
\hline Hispanic & 651 & 0.79 \\
\hline African-American & 110 & 0.70 \\
\hline Asian & 101 & 0.86 \\
\hline Mixed & 63 & 0.76 \\
\hline Other/unknown & 38 & 0.60 \\
\hline \multicolumn{3}{|l|}{ Gender } \\
\hline Female & 1095 & 0.80 \\
\hline Male & 962 & 0.78 \\
\hline \multicolumn{3}{|l|}{ Overweight at entry } \\
\hline No & 1778 & 0.79 \\
\hline Yes & 279 & 0.77 \\
\hline \multicolumn{3}{|l|}{ Parental history of asthma } \\
\hline No & 1651 & 0.80 \\
\hline Yes & 273 & 0.79 \\
\hline \multicolumn{3}{|l|}{ History of allergic rhinitis } \\
\hline No & 1688 & 0.79 \\
\hline Yes & 322 & 0.78 \\
\hline \multicolumn{3}{|l|}{ Humidifier use } \\
\hline No & 1470 & 0.80 \\
\hline Yes & 497 & 0.77 \\
\hline \multicolumn{3}{|c|}{ Maternal smoking during pregnancy } \\
\hline No & 1700 & 0.80 \\
\hline Yes & 293 & 0.74 \\
\hline \multicolumn{3}{|l|}{ Postnatal maternal smoking } \\
\hline No & 1830 & 0.80 \\
\hline Yes & 189 & 0.74 \\
\hline \multicolumn{3}{|c|}{ Household second hand smoking } \\
\hline No & 1658 & 0.80 \\
\hline Yes & 357 & 0.76 \\
\hline \multicolumn{3}{|l|}{ Pests in home } \\
\hline No & 1455 & 0.76 \\
\hline Yes & 923 & 0.80 \\
\hline \multicolumn{3}{|l|}{ Dogs in home } \\
\hline No & 923 & 0.79 \\
\hline Yes & 1134 & 0.79 \\
\hline \multicolumn{3}{|l|}{ Pets in home } \\
\hline No & 495 & 0.79 \\
\hline Yes & 1562 & 0.79 \\
\hline \multicolumn{3}{|l|}{ Health insurance } \\
\hline No & 358 & 0.78 \\
\hline Yes & 1661 & 0.79 \\
\hline \multicolumn{3}{|l|}{ Parental income (US\$/year) } \\
\hline$\leqslant 14999$ & 307 & 0.74 \\
\hline $15000-49999$ & 749 & 0.79 \\
\hline$>50000$ & 697 & 0.81 \\
\hline \multicolumn{3}{|l|}{ Parental education } \\
\hline Less than high school & 295 & 0.77 \\
\hline At least high school & 392 & 0.79 \\
\hline Some college & 822 & 0.79 \\
\hline College and above & 464 & 0.81 \\
\hline \multicolumn{3}{|l|}{ Cohort } \\
\hline 1993 & 1046 & 0.80 \\
\hline 1996 & 1011 & 0.78 \\
\hline
\end{tabular}

\section{Lung function and asthma}

There were 212 new cases of asthma resulting in an incidence rate of 16.1/1000 person-years. The incidence of newly diagnosed asthma was inversely associated with measures of airflow at study entry (see table E4 in online supplement available at http://thorax.bmj.com/supplemental). For example, the incidence rate of newly diagnosed asthma increased from 9.5/1000 person-years for children with percentage predicted $\mathrm{FEF}_{25-75}$ values $\geqslant 120 \%$ to $20.4 / 1000$ person-years for children with $\mathrm{FEF}_{25-75}$ values $\leqslant 100 \%$. A similar inverse relationship was observed for $\mathrm{FEV}_{1}$ but was less clear for FVC.

Over the 10th-90th percentile range for $\mathrm{FEF}_{25-75}$ (57.1) the hazard ratio (HR) of new onset asthma was 0.50 (95\% CI 0.35 to 0.71 ), table 2. A similar significant inverse association was observed for $\mathrm{FEV}_{1}$. The results from lagged models were very similar to the baseline analysis, except for FVC where a statistically significant inverse relationship was also observed between FVC and new onset asthma. These inverse associations were not confounded or modified by birth weight, premature birth, parental history of asthma, history of allergy, second hand smoke, current and in utero maternal smoking, personal smoking, physical activity, health insurance, overweight or by parental income or education.

\section{Interrelationship between ambient air pollution, lung function and new onset asthma}

The incidence rates across lung function categories differed markedly between "high" (13.7-29.5 $\left.\mu \mathrm{g} / \mathrm{m}^{3}\right)$ and "low" (5.7$8.5 \mu \mathrm{g} / \mathrm{m}^{3}$ ) $\mathrm{PM}_{2.5}$ communities (table 3). The incidence rate of asthma for $\mathrm{FEF}_{25-75} \geqslant 120 \%$ in the "high" $\mathrm{PM}_{2.5}$ communities was 15.9/1000 person-years compared with 6.4/1000 personyears in "low" $\mathrm{PM}_{2.5}$ communities. However, there was little difference in the incidence rate of asthma for $\mathrm{FEF}_{25-75} 80-100 \%$ in the "high" and "low" $\mathrm{PM}_{2.5}$ communities. In addition, loss of protection by high lung function against new onset asthma in the "high" $\mathrm{PM}_{2.5}$ communities was observed for all of the lung function measures. Over the 10th-90th percentile range of $\mathrm{FEV}_{25-75}$, for example, the HR of new onset asthma was 0.34 (95\% CI 0.21 to 0.56 ) in the "low" $\mathrm{PM}_{2.5}$ communities, whereas this protective effect was reduced to 0.76 (95\% CI 0.45 to 1.26 ) in the "high" $\mathrm{PM}_{2.5}$ communities (table 4). There were no substantial differences in the effect of lung function between "high" and "low" ozone communities.

Using a hierarchical model, we evaluated the effect of individual air pollutants $\left(\mathrm{NO}_{2}, \mathrm{PM}_{10}, \mathrm{PM}_{2.5}\right.$, acid vapour, ozone and elemental and organic carbon) on the association between lung function and asthma (fig 1). The loss of the protective effect from better lung function can be appreciated from the graphs. The modifying effect of $\mathrm{PM}_{2.5}, \mathrm{PM}_{10}$ and organic carbon was statistically significant $(\mathrm{p} \leqslant 0.05)$ and that of $\mathrm{NO}_{2}$, elemental carbon and acid vapour was marginally significant $(p \leqslant 0.08)$. Of all the pollutants, $\mathrm{PM}_{2.5}$ appeared to have the strongest modifying effect on the association between lung function with asthma as it had the highest $R^{2}$ value (0.42). For each $57.1 \%$ (10th-90th range) change in $\mathrm{FEF}_{25-75}$, the risk of asthma decreased by 0.35 -fold in a community with ambient $\mathrm{PM}_{2.5}$ levels of $10 \mu \mathrm{g} / \mathrm{m}^{3}$ whereas this protective effect was attenuated to 0.90 -fold in a community with ambient $\mathrm{PM}_{2.5}$ levels of $25 \mu \mathrm{g} / \mathrm{m}^{3}$ (fig 1 ).

\section{Sensitivity analysis}

To assess the effects of potential misclassification of new onset asthma we limited the definition of incident asthma cases to those who also reported recent use of inhalers. The observed associations were similar to the primary analysis (see tables E5 and E6, model 1, in online supplement available at http:// thorax.bmj.com/supplemental). Restricting the analysis to children aged 10 years or less at study entry (see tables E5 and E6, model 2, in online supplement available at http:// thorax.bmj.com/supplemental) or children without extreme values of lung function (5th-95th percentile) (see tables E5 and E6, model 3, in online supplement available at http:// thorax.bmj.com/supplemental) also did not alter our initial findings. The association also remained unchanged after adjusting for ambient $\mathrm{PM}_{2.5}$ (see table E5, model 4, in online supplement available at http://thorax.bmj.com/supplemental) 
Table 2 Association between newly diagnosed asthma and lung function at study entry, and lung function 1 and 2 years before asthma diagnosis

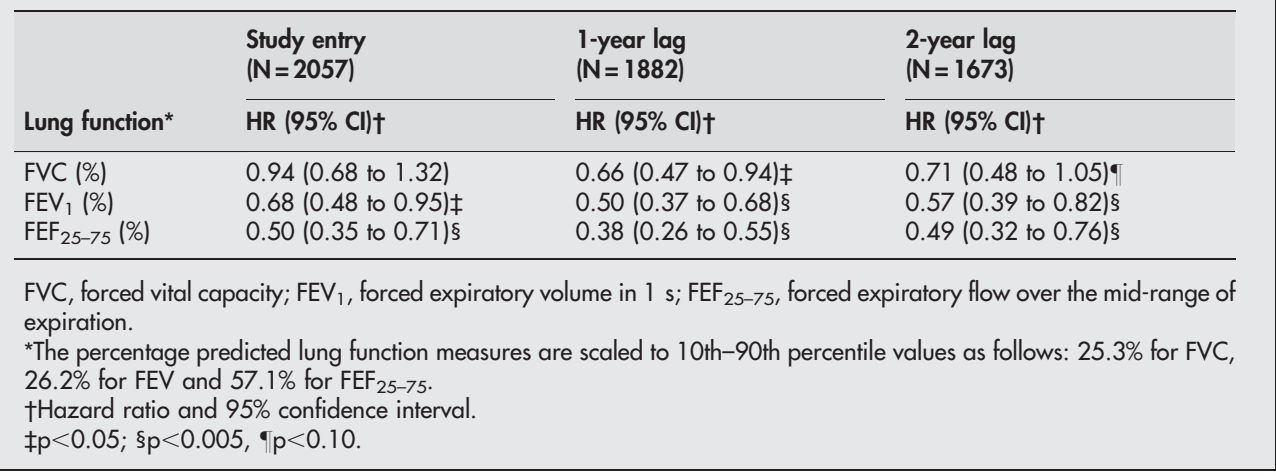

and risk factors of low lung function after birth, ie, preterm birth, birth weight, maternal smoking during pregnancy and parental history of asthma (tables E5 and E6, model 4, in online supplement available at http://thorax.bmj.com/supplemental).

\section{DISCUSSION}

The joint effect of air pollution and lung function in the development of asthma during adolescence has not been characterised previously. The results of this study show that better airflow, characterised by higher $\mathrm{FEF}_{25-75}$ and $\mathrm{FEV}_{1}$ during childhood, was associated with a decreased risk of new onset asthma during adolescence. However, exposure to high levels of $\mathrm{PM}_{2.5}$ (or $\mathrm{PM}_{10}, \mathrm{NO}_{2}$, acid vapour, elemental carbon or organic carbon) attenuated this protective association of lung function on the occurrence of asthma.

Although the protective effect of better lung function on the development of asthma has been observed in other studies, the attenuation of this effect with increasing levels of particulate and related non-ozone pollutants is a new observation. The explanation of this pattern of effects is unclear. However, chronic inflammation and resulting airway remodelling is a central pathophysiological characteristic of asthma ${ }^{18}$ and, in

Table 3 Incidence rate (IR) with $95 \% \mathrm{Cl}$ of new onset asthma stratified by community-specific annual average $\mathrm{PM}_{2.5}$ (and other non-ozone pollutant) levels (1994-2001)*

\begin{tabular}{|c|c|c|}
\hline \multirow[b]{2}{*}{ Lung function } & \multirow{2}{*}{$\frac{\text { Low } \mathrm{PM}_{2.5}}{\mathrm{IR}(95 \% \mathrm{Cl}) \dagger}$} & \multirow{2}{*}{$\frac{\text { High } \mathrm{PM}_{2.5}}{\text { IR }(95 \% \mathrm{Cl}) \dagger}$} \\
\hline & & \\
\hline \multicolumn{3}{|l|}{ FVC (\% predicted) } \\
\hline$\leqslant 90$ & $19.4(7.5$ to 50.5$)$ & $14.2(5.1$ to 39.6$)$ \\
\hline 90-110 & $16.8(7.0$ to 40.1$)$ & 25.6 (11.1 to 59.2 \\
\hline$>110$ & 7.9 (2.9 to 21.9 ) & $16.7(6.5$ to 42.9$)$ \\
\hline \multicolumn{3}{|l|}{$\mathrm{FEV}_{1}$ (\% predicted) } \\
\hline$\leqslant 90$ & 23.7 (9.4 to 59.4$)$ & 20.8 (8.0 to 54.0 ) \\
\hline (90-110 & 15.6 (6.5 to 37.4 ) & 23.1 (10.0 to 53.7 ) \\
\hline$>110$ & 6.5 (2.3 to 18.7$)$ & 18.8 (7.5 to 47.3 ) \\
\hline \multicolumn{3}{|c|}{$\mathrm{FEF}_{25-75}(\%$ predicted $)$} \\
\hline $80-100$ & 21.1 (8.8 to 50.5 ) & 23.8 (10.2 to 55.6 \\
\hline $100-120$ & 11.9 (4.7 to 30.0$)$ & $23.9(9.9$ to 57.7$)$ \\
\hline$\geqslant 120$ & 6.4 (2.3 to 18.2$)$ & $15.9(6.3$ to 40.5$)$ \\
\hline Overall IR (95\% Cl) & $14.2(7.0$ to 28.7$)$ & 18.4 (9.4 to 35.9 ) \\
\hline
\end{tabular}

$\mathrm{FVC}$, forced vital capacity; $\mathrm{FEV}_{1}$, forced expiratory volume in $1 \mathrm{~s}$; $\mathrm{FEF}_{25-75}$, forced expiratory flow over the mid-range of expiration; $\mathrm{PM}_{2.5}$, particulate matter with an aerodynamic diameter of $<2.5 \mu \mathrm{m}$.

*The 12 communities were grouped by annual $\mathrm{PM}_{2.5}$ level into six high $\left(13.7-29.5 \mu \mathrm{g} / \mathrm{m}^{3}\right)$ and six low $\left(5.7-8.5 \mu \mathrm{g} / \mathrm{m}^{3}\right)$ communities. However, the same grouping and estimates would occur if the communities were grouped by $\mathrm{NO}_{2}, \mathrm{PM}_{10}$, acids, elemental carbon or organic carbon. tAdjusted incidence rate of newly diagnosed asthma (per 1000 personyears) for different categories of lung function is reported by high and low $\mathrm{PM}_{2.5}$ (non-ozone pollutant) communities, adjusted for community, sex and race/ethnicity. one necroscopic study, chronic exposure to high levels of particulate air pollution was associated with small airway remodelling characterised by increase in fibrous tissue and smooth muscle in respiratory bronchioles. ${ }^{12}$ The authors concluded that those changes could result in chronic airflow obstruction. Furthermore, exposure to a high level of particulate matter and ozone was associated with radiological evidence of bronchiolar disease and mild bronchial wall thickening on CT scans in children 5-13 years of age. ${ }^{19}$ In our study it is possible that chronic inflammation in the distal airways induced by air pollution led to remodelling of the airways that modified the protection conferred by better lung function (or associated risk factors) on the subsequent development of asthma.

We have interpreted our results as a protective effect of better lung function that was attenuated by the effects of air pollution. Our data do not support an alternative hypothesis that particulate air pollution increased rates of incident asthma among children with poor lung function at study entry because rates among those with poor lung function were similar in both low and high pollution communities (table 3 ). This interpretation is also consistent with previous analyses in this cohort in which we found that the reduced risk of asthma associated with the TNF $\alpha-308$ GG genotype (a promoter variant of tumour necrosis factor) was attenuated by ambient ozone levels. ${ }^{8}$ It is therefore likely that evolutionary selection has resulted in lung structure and other characteristics that promote better respiratory health. Better lung function may be a marker for lower susceptibility to airway pathophysiology.

Higher flow rates are well correlated with a lower prevalence of airway hyper-reactivity, ${ }^{20-22}$ a phenotype characteristic of asthma which has common genetic determinants with the disease. $^{23}$ Furthermore, it has been observed that the agerelated decline in the prevalence of airway hyper-reactivity is larger among those with higher $\mathrm{FEV}_{1} \%{ }^{24}$

Our results are consistent with the limited number of previous cohort studies that have found that higher flow rates in school children were associated with a lower risk of asthma and wheezing in adults. ${ }^{25} 26$ Because our cohort was not recruited at birth, we could not evaluate the effect of lung function very early in life on the risk of asthma. Studies that measured lung function in the first month ${ }^{10}$ or first year ${ }^{11}$ of life showed that lung function tracked throughout childhood and adolescence. However, the association between early life lung function and subsequent development of wheeze and asthma was not consistent in these studies. In a US study, lung function during the first year of life was associated with subsequent late onset or persistent wheeze but not with transient wheeze. ${ }^{27}$ An Australian study reported that lung function in the first month of life was associated with persistent wheeze but not with transient or late onset wheeze. ${ }^{10}$ 
Table 4 Risk of new onset asthma by lung function, scaled to the 10th-90th percentile range, stratified by community-specific annual average $\mathrm{PM}_{2.5}$ levels (1994-2003)*

\begin{tabular}{|c|c|c|c|}
\hline & Low $\mathrm{PM}_{2.5}$ & High $\mathrm{PM}_{2.5}$ & \\
\hline Lung function & $\mathrm{HRT}(95 \% \mathrm{Cl})$ & HRt $(95 \%$ Cl) & Interaction $\mathrm{p}$ valueł \\
\hline $\begin{array}{l}\text { FVC (\% predicted) } \\
\mathrm{FEV}_{1}(\% \text { predicted }) \\
\mathrm{FEF}_{25-75}(\% \text { predicted })\end{array}$ & $\begin{array}{l}0.65(0.41 \text { to } 1.03) \S \\
0.46(0.30 \text { to } 0.71)^{\top} \\
0.34(0.21 \text { to } 0.56)^{-}\end{array}$ & $\begin{array}{l}1.41(0.87 \text { to } 2.26) \\
1.08(0.66 \text { to } 1.76) \\
0.76(0.45 \text { to } 1.26)\end{array}$ & $\begin{array}{l}0.02 \\
0.01 \\
0.03\end{array}$ \\
\hline
\end{tabular}

FVC, forced vital capacity; $\mathrm{FEV}_{1}$, forced expiratory volume in $1 \mathrm{~s}$; $\mathrm{FEF}_{25-75}$, forced expiratory flow over the mid-range of expiration; $\mathrm{PM}_{2.5}$, particulate matter with an aerodynamic diameter of $<2.5 \mu \mathrm{m}$.

"The 12 communities were grouped by annual $\mathrm{PM}_{2.5}$ level into six "high" and six "low" communities. However, the same grouping and estimates would occur if the communities were grouped by $\mathrm{NO}_{2}, \mathrm{PM}_{10}$, acid, elemental carbon or organic carbon.

HHazard ratio (HR) and 95\% confidence interval of newly diagnosed asthma, scaled to the 10th-90th percentile range for each lung function, $\left(25.3 \%\right.$ for FVC, $26.2 \%$ for $\mathrm{FEV}_{1}$ and $57.1 \%$ for $\left.\mathrm{FEF}_{25-75}\right)$. All models were adjusted for community and race/ethnicity with age- and sex-specific baseline hazard.

fInteraction $p$ value based on likelihood ratio tests.

$\S p<0.10 ; \uparrow p<0.001$.

It is possible that different constitutive factors such as genetic predisposition $^{28}$ and environmental exposures such as maternal smoking or other air pollutants ${ }^{28}$ or sensitivity to different allergens influenced the pattern of wheeze associated with early deficits of lung function. ${ }^{10}{ }^{29}$ A recent study of a Norwegian birth cohort found that better lung function within days of birth was associated with a lower prevalence of asthma (16.2\%) by age 10 compared with those with worse lung function $(24.3 \%)$ after birth. However, the authors concluded that lung function ascertained within a few days of birth was not a good predictor of asthma at age 10 as the positive predictive value for asthma ranged from 24.3 to $31.3 .^{9}$

The strength of our study was the 8-year follow-up of children in the fourth grade and the collection of their yearly lung function, asthma diagnosis and air pollution exposure in a consistent manner. The observed incidence rate of physiciandiagnosed asthma in the present study (16.1 cases/1000 personyears) was similar to the increasing occurrence of asthma in
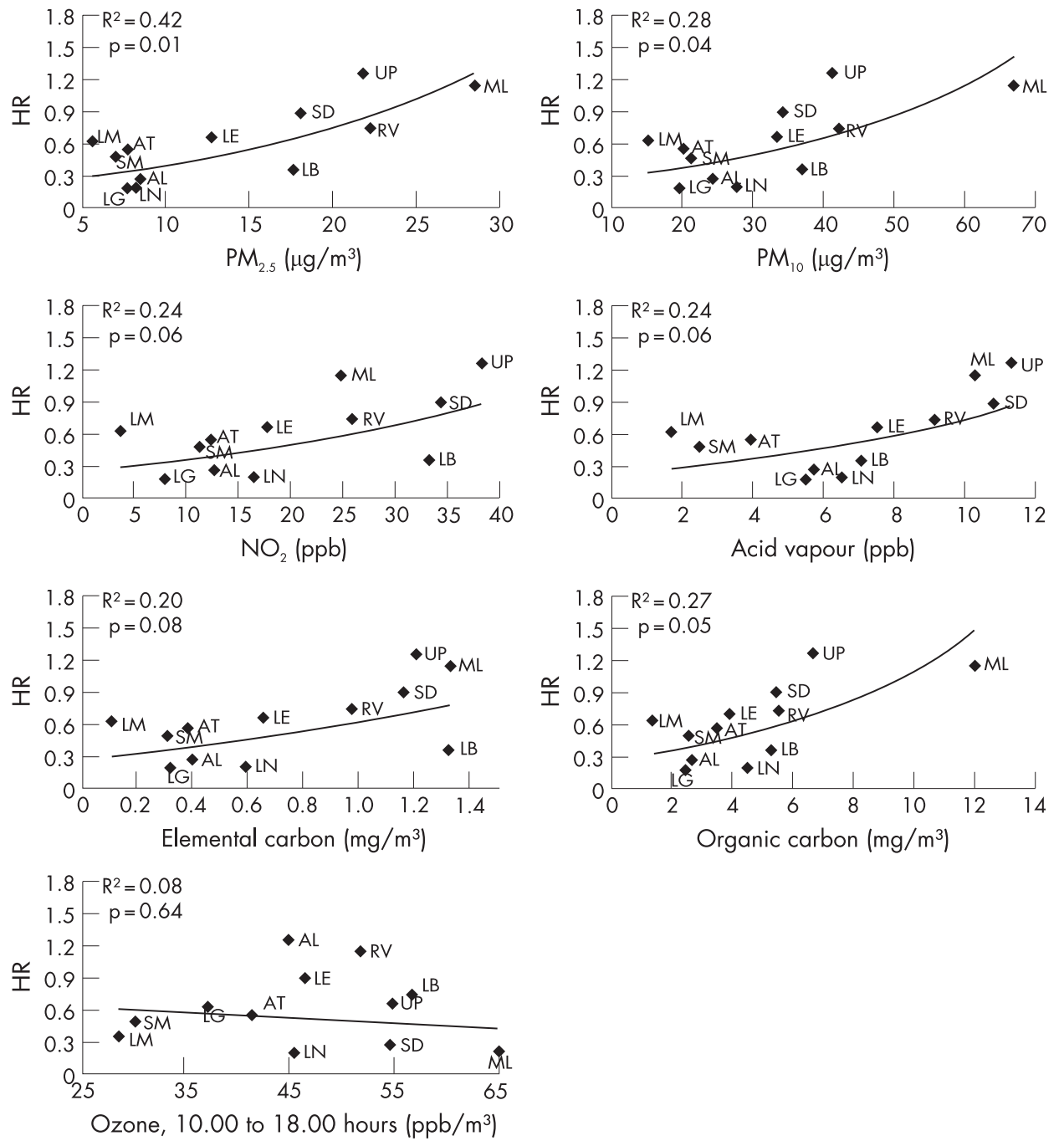
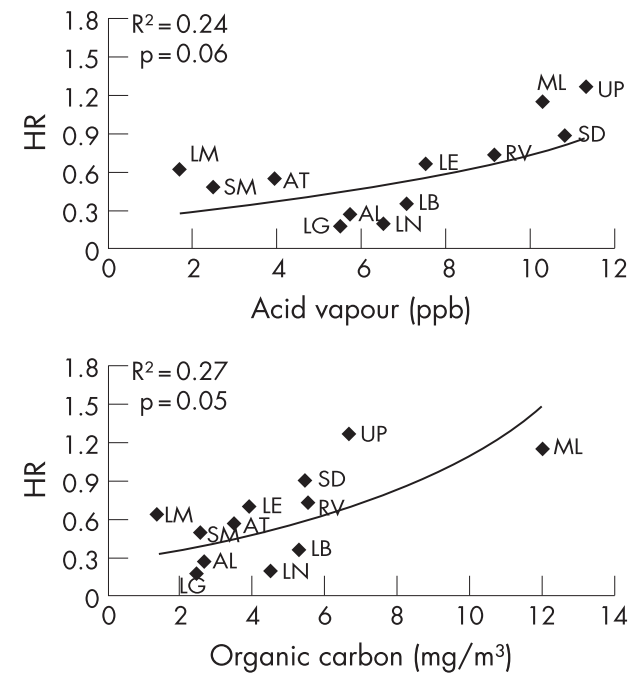

Figure 1 Community-specific hazard ratio (HR) of newly diagnosed asthma over 10th90th percentile range $(57.1 \%)$ of forced expiratory flow over the mid-range of expiration ( $\left.\mathrm{FEF}_{25-75 \%}\right)$ by average levels of different ambient pollutants. $\mathrm{PM}_{2.5}$, particulate matter with an aerodynamic diameter $<2.5 \mu \mathrm{m} ; \mathrm{PM}_{10}$, particulate matter with an aerodynamic diameter $<10 \mu \mathrm{m}$; $\mathrm{NO}_{2}$, nitrogen dioxide. 
recent decades in children. ${ }^{30-33}$ The retention rate in this cohort is similar to other longitudinal studies involving children with lung function assessments, ${ }^{27}{ }^{34}$ with an observed follow-up of $79 \%$ of the total possible person-years. Furthermore, the 521 children excluded from the study because of insufficient follow-up data did not differ from those included in this analysis with respect to covariates pertinent to the incidence of asthma (see table E3 in online supplement available at http:// thorax.bmj.com/supplemental).

As this is not a birth cohort study, the temporal relationship between lung function and asthma diagnosis remains a potential concern. Because low lung function tracks over time and is associated with different patterns of wheeze, ${ }^{10} 27$ it is possible that the cases of new onset asthma in our study were undiagnosed cases of asthma and had low lung function at study entry. This seems unlikely because children with any history of wheeze or asthma as well as children without a history of wheezing at study entry were excluded ( $\sim 40 \%$ of the cohort). Furthermore, the flow rates at study entry in children who developed new onset asthma were significantly higher than those of children with early transient or early persistent wheeze (see Lung function by wheeze status in online supplement available at http://thorax.bmj.com/supplemental) who could have low lung function ${ }^{10} 1127$ and might be misclassified as "non-asthmatic" at study entry by forgetful parents. The observed associations also remained essentially unchanged even after removing those with extreme values (see tables E5 and E6, model 3, in online supplement available at http://thorax.bmj.com/supplemental). Furthermore, if the observed association between flow rates and new onset asthma were mediated through early low lung function, then adjustment for risk factors for low lung function after birth and ambient $\mathrm{PM}_{2.5}$ should have attenuated the effects of lung flow on the risk of asthma. However, we did not observe any such effect (see tables E5 and E6, model 4, in online supplement available at http://thorax.bmj.com/supplemental). Tracking of lung function, undiagnosed pre-existing asthma and low lung function at study entry due to ambient $\mathrm{PM}_{2.5}$ level are therefore unlikely to explain our results.

Another potential limitation of our study could be the accuracy of new onset asthma as it was based on personal interview of the children; however, a recent study noted that children as young as 7 years can provide information regarding their asthma with an acceptable level of validity and reliability. ${ }^{35}$ In our analysis we addressed the possibility that some children might have pre-existing undiagnosed asthma by excluding incident asthma cases diagnosed within the first 2 years of follow-up in the lagged time-dependent analysis. The similarity in the associations between the time-dependent lagged and baseline models makes it unlikely that the observed associations were only due to misclassification of asthma status at cohort entry or during follow-up.

Another potential concern may be that the results of this study are due to chance as we have used three different lung function measurements and tested interaction with ozone and the six correlated non-ozone pollutants. However, we do not think this is the case as the choice of the lung function measurements and the pollutants are based on a priori hypothesis $^{15}$ and all the results show a consistent pattern. Furthermore, the lung function parameters and the non-ozone group of pollutants are correlated so a Bonferroni type of adjustment is not appropriate in this setting.

In conclusion, our data suggest that better lung function during childhood provides protection against the development of asthma during adolescence. However, this protective effect of better lung function was attenuated by exposure to higher levels of ambient particulate matter $\left(\mathrm{PM}_{2.5}\right.$ and $\left.\mathrm{PM}_{10}\right), \mathrm{NO}_{2}$, acid vapour and elemental and organic carbon. Further research is needed to clarify the mechanism by which air pollution modifies the protective effect of better lung function on the development of asthma.

\section{ACKNOWLEDGEMENTS}

We acknowledge all the participants and their parents of the CHS Study, as well as all the teachers and staff of the participating schools. Without their active participation we would not be able to address these intriguing and important aspects of respiratory health in children and adolescents. We are also grateful to the members of our experienced field team whose conscientious and courteous work ethic enabled us to gather this immense data efficiently. We also thank our colleagues who are involved in the maintenance and quality control of the database.

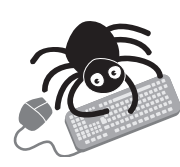

Further details are given in the online supplement available at http://thorax.bmj.com/supplemental.

\section{Authors' affiliations \\ Talat Islam, W James Gauderman, Kiros Berhane, Rob McConnell, Ed \\ Avol, John M Peters, Frank D Gilliland, Department of Preventive} Medicine, Keck School of Medicine, University of Southern California, Los Angeles, California, USA

This work was supported by the Southern California Environmental Health Sciences Center (grant number 5P30ES007048) funded by the National Institute of Environmental Health Sciences; the Children's Environmental Health Center (grant numbers 5P01ES009581, R826708-01 and RD831861-01) funded by the National Institute of Environmental Health Sciences and the Environmental Protection Agency; the National Institute of Environmental Health Sciences (grant number 5P01ES011627); the National Heart, Lung and Blood Institute (grant numbers 5R01HL61768 and 1R01HL76647); the California Air Resources Board (contract number 94-331); and the Hastings Foundation. The study sponsors had no role in the study design; the collection, analysis and interpretation of data; the writing of the report; or in the decision to submit the paper for publication.

Competing interests: None.

\section{REFERENCES}

1 Akinbami L. The state of childhood asthma, United States, 1980-2005. Adv Data 2006: 1-24

2 Reed CE. The natural history of asthma. J Allergy Clin Immunol 2006;1 18:543-50.

3 Gilmour MI, Jaakkola MS, London SJ, et al. How exposure to environmental tobacco smoke, outdoor air pollutants, and increased pollen burdens influences the incidence of asthma. Environ Health Perspect 2006;1 14:627-33.

4 Delfino RJ. Epidemiologic evidence for asthma and exposure to air toxics: linkages between occupational, indoor, and community air pollution research. Environ Health Perspect, 2002;110(Suppl 4), 573-89.

5 McConnell R, Berhane K, Yao L, et al. Traffic, susceptibility, and childhood asthma. Environ Health Perspect 2006;1 14:766-72.

6 Peters JM, Avol E, Gauderman WJ, et al. A study of twelve Southern California communities with differing levels and types of air pollution. II. Effects on pulmonary function. Am J Respir Crit Care Med 1999;159:768-75.

7 Peters JM, Avol E, Navidi W, et al. A study of twelve Southern California communities with differing levels and types of air pollution. I. Prevalence of respiratory morbidity. Am J Respir Crit Care Med 1999;159:760-7.

8 Li YF, Gauderman WJ, Avol E, et al. Associations of tumor necrosis factor G308A with childhood asthma and wheezing. Am J Respir Crit Care Med 2006;173:970-6

9 Haland G, Carlsen KC, Sandvik L, et al. Reduced lung function at birth and the risk of asthma at 10 years of age. N Engl J Med 2006;355:1682-9.

10 Turner SW, Palmer U, Rye PJ, et al. The relationship between infant airway function, childhood airway responsiveness, and asthma. Am J Respir Crit Care Med 2004;169:921-7.

11 Martinez FD, Wright AL, Taussig LM, et al. Asthma and wheezing in the first six years of life. The Group Health Medical Associates. N Engl J Med 1995;332:133-8

12 Churg A, Braver M, del Carmen Avila-Casado M, et al. Chronic exposure to high levels of particulate air pollution and small airway remodeling. Environ Health Perspect 2003;111:714-8.

13 Higgins BG, Francis HC, Yates C, et al. Environmental exposure to air pollution and allergens and peak flow changes. Eur Respir J 2000;16:61-6. 
14 Balmes JR, Chen LL, Scannell C, et al. Ozone-induced decrements in FEV 1 and FVC do not correlate with measures of inflammation. Am J Respir Crit Care Med 1996:153:904-9.

15 Gauderman WJ, Avol E, Gilliland F, et al. The effect of air pollution on lung development from 10 to 18 years of age. N Engl J Med 2004;351:1057-67.

16 CDC. SAS code for calculating percentiles and Z-scores. http://www.colc.gov/ nccdphp/dnpa/growthcharts/sas.htm.

17 Berhane K, Gauderman W, Stram D, et al. Statistical issues in studies of the long term effects of air pollution: the Southern California Children Health Study (with discussion). Stat Sci 2004;19:414-49.

18 Vignola AM, Chanez P, Bonsignore $G$, et al. Structural consequences of airway inflammation in asthma. J Allergy Clin Immunol 2000;105:S514-7.

19 Calderon-Garciduenas L, Mora-Tiscareno A, Fordham LA, et al. Lung radiology and pulmonary function of children chronically exposed to air pollution. Environ Health Perspect 2006; 114:1432-7.

20 Ciprandi G, Cirillo I, Vizzaccaro A, et al. Early bronchial airflow impairment in patients with persistent allergic rhinitis and bronchial hyperreactivity. Respir Med 2005;99:1606-12.

21 Cirillo I, Klersy C, Marseglia GL, et al. Role of $\mathrm{FEF}_{25 \%-75 \%}$ as a predictor of bronchial hyperreactivity in allergic patients. Ann Allergy Asthma Immunol 2006;96:692-700.

22 Litonjua AA, Sparrow D, Weiss ST. The $\mathrm{FEF}_{25-75} / \mathrm{FVC}$ ratio is associated with methacholine airway responsiveness. The Normative Aging Study. Am J Respir Crit Care Med 1999;159:1574-9.

23 Clarke JR, Jenkins MA, Hopper JL, et al. Evidence for genetic associations between asthma, atopy, and bronchial hyperresponsiveness: a study of 8 to 18year-old twins. Am J Respir Crit Care Med 2000;162:2188-93.

24 Ulrik CS, Backer V. Longitudinal determinants of bronchial responsiveness to inhaled histamine. Chest 1998;113:973-9.
25 Toelle BG, Xuan W, Peat JK, et al. Childhood factors that predict asthma in young adulthood. Eur Respir J 2004;23:66-70.

26 Jenkins MA, Hopper JL, Bowes G, et al. Factors in childhood as predictors of asthma in adult life. BMJ 1994;309:90-3.

27 Morgan WJ, Stern DA, Sherrill DL, et al. Outcome of asthma and wheezing in the first 6 years of life: follow-up through adolescence. Am J Respir Crit Care Med $2005 ; 172: 1253-8$.

28 Young S, Arnott J, O'Keeffe PT, et al. The association between early life lung function and wheezing during the first 2 yrs of life. Eur Respir J 2000;15:151-7.

29 Rhodes HL, Thomas P, Sporik R, et al. A birth cohort study of subjects at risk of atopy: twenty-two-year follow-up of wheeze and atopic status. Am J Respir Crit Care Med 2002;165:176-80.

30 Beckett WS, Jacobs DR Jr, Yu X, et al. Asthma is associated with weight gain in females but not males, independent of physical activity. Am J Respir Crit Care Med 2001; 164:2045-50.

31 Norrman E, Nystrom L, Jonsson E, et al. Prevalence and incidence of asthma and rhinoconjunctivitis in Swedish teenagers. Allergy 1998;53:28-35.

32 Ronmark E, Jonsson E, Platts-Mills T, et al. Incidence and remission of asthma in schoolchildren: report from the Obstructive Lung Disease in Northern Sweden studies. Pediatrics 2001;107:e37.

33 Strachan DP, Butland BK, Anderson HR. Incidence and prognosis of asthma and wheezing illness from early childhood to age 33 in a national British cohort. BMJ 1996:312:1195-9.

34 Sears MR, Greene JM, Willan AR, et al. A longitudinal, population-based, cohort study of childhood asthma followed to adulthood. N Engl J Med 2003;349:1414-22.

35 Olson LM, Radecki L, Frintner MP, et al. At what age can children report dependably on their asthma health status? Pediatrics 2007;1 19:e93-102.

\section{LUNG ALERT}

\section{High index of suspicion required when screening new entrants for tuberculosis}

$\Delta$ Laifer G, Widmer AF, Simcock $M$, et al. TB in a low-incidence country: differences between new immigrants, foreign-born residents and native residents. Am J Med 2007;120:350-6.

$\mathrm{n}$ this Swiss study, the authors divided 385 patients with suspected tuberculosis (TB) into three groups: immigrants, foreign-born residents (from moderate- to high-incidence countries) and native residents. Immigrants displaying an abnormal chest radiograph on entry to the country were compared with the other two groups who had suspected TB. Each of the groups was assessed for clinical signs and symptoms of TB, laboratory markers of inflammation and sputum culture.

The results showed that new immigrants who were later diagnosed as having active TB, either on the basis of culture results or response to treatment, failed to display traditional clinical signs and symptoms ( $17 \%$ of immigrants had night sweats, compared with $39 \%$ of native residents) and mounted a lower inflammatory response systemically. Seventy three per cent of immigrants had a normal $\mathrm{C}$ reactive protein level, with the mean being $17 \mathrm{~g} / \mathrm{l}$ compared with a mean of $67.1 \mathrm{~g} / \mathrm{l}$ in foreign-born residents and $90 \mathrm{~g} / \mathrm{l}$ in native residents. The immigrant population group also yielded fewer positive sputum cultures but had a higher proportion of multi-drug resistant strains. It appeared that the main factor leading to a diagnosis of TB in the immigrant group was an abnormal chest radiograph.

The authors concluded that a chest radiograph alongside rapid diagnostic tests, including sputum smear and PCR, seemed to be most effective at reaching the correct diagnosis rapidly. The authors do point out that the differences in clinical features seen may be due to selection bias because all new entrants were screened, whereas only residents who presented with disease were included in the study. Nonetheless, it is important to carefully work up new entrants with abnormal chest radiographs-a message particularly important in countries with low incidence rates for $\mathrm{TB}$. The authors suggest that post-migration follow-up in addition to active testing should be reinforced to prevent the slippage of positive individuals through the net of passive testing.

Mathi Rasanesan Senior House Officer in Respiratory Medicine, Homerton University Hospital, UK; mathir@doctors.org.uk 